\title{
PROTOTYPING OF MODEL RC PLANE FOR AGRICULTURAL APPLICATION
}

Atif Saeed

Department of Mechatronics Engineering, SZABIST

Karachi (Pakistan).

E-mail: m.atif@szabist.edu.pk

ORCID: https://orcid.org/0000-0003-4369-2388

Syed Ammad U1 Raza Kazmi

Department of Mechatronics Engineering, SZABIST

Karachi (Pakistan).

E-mail: ammadkazmi98@gmail.com

ORCID: https://orcid.org/0000-0001-6354-1662

Moiz Motani

Department of Mechatronics Engineering, SZABIST

Karachi (Pakistan).

E-mail: moizmotani@gmail.com

ORCID: https://orcid.org/0000-0002-6323-060X

Muhammad Baqar Panjwani

Department of Mechatronics Engineering, SZABIST

Karachi (Pakistan).

E-mail: baqar1015@gmail.com

ORCID: https://orcid.org/0000-0003-3607-299X

Recepción: 10/09/2021 Aceptación: 03/11/2021 Publicación: 14/02/2022

\section{Citación sugerida:}

Saeed, A., Raza, S. A., Motani, M., y Panjwani, M. B. (2022). Prototyping of Model RC Plane for Agricultural Application. 3C Tecnología. Glosas de innovación aplicadas a la pyme, Edición Especial, (febrero 2022), 137-149. https://doi.org/10.17993/3ctecno.2022.specialissue9.137-149 


\section{ABSTRACT}

A radio controlled plane ( $\mathrm{RC}$ Plane) is a small flying machine that is controlled from the ground by transmitter. The plane is piloted with the help of a transmitter that communicates with a receiver and sends signals to it. The plane has servos on board. These are governed by same aerodynamic. The rules governing small aircrafts are the same as those governing large aircrafts. The aircraft under consideration in this study was intended to have optimum lift and drag properties. This was accomplished by determining the best values for fuselage length, wingspan, and other parameters. As this RC place is to be used for the agricultural and disinfectant spraying purpose, The dimensions of the elevator and rudder, as well as the total weight, were determined through different analyses. These analysis were done using solid works software.

We build this RC plane to achieve two different goals. The first one is making farmers job easier, faster and much more effective. Our second goal was to use this RC plane for sanitization and spraying disinfectant as during covid 19 a number lives were lost because the process of spraying disinfectant was too slow which lead to the spread of corona virus through our surroundings.

\section{KEYWORDS}

RC plane, Designing, Analysis, Specifications. 


\section{INTRODUCTION}

Our purpose of designing and fabricating this $\mathrm{RC}$ plane was to use it agricultural and healthcare purpose. The designing of this plane required different analysis and other electronic parts were used for its building purpose. The first objective was to study aerodynamics of this RC plane and use right parts to make it fly efficiently. The controlling of RG plane is done by a transmitter and receiver. The transmitter we used is (Fly sky i6X) and receiver used is (Fly sky iA6B).

The RG plane works on same principle as of a big aircraft what makes it different is its scaling, Reynolds number, wing loading and its moment of inertia. The wing loading of an $\mathrm{R} / \mathrm{C}$ model is one to two orders of magnitude less than that of a full-scale airplane (due to the "square-cube law"). Wing loadings on R/C models are typically 1-2 lb/ft2 (16-32 oz/ft2). Whereas full scale planes are larger than 10 (Cessna 172 has a density of 12.6 $\mathrm{lb} / \mathrm{ft} 2$ ). The result is lower stall speeds, as well as lower take-off and landing speeds and distances between landing (Azeez et al., 2019). The Reynolds number of RC plane is less than 500,000 (Azeez et al., 2019) as compared to big aircrafts with have Reynolds number greater than 1 million.

After getting a good amount of knowledge from literature review, CFD analysis was done using solidworks on our final design of RC plane so we can get the best possible lift and drag. The designing process of this planes requires use to choose suitable part to achieve better weight optimization according to our desired applications (Visnuprasad et al., 2019).

\section{METHODOLOGY}

\subsection{DESIGNING AND BUILDING RC PLANE}

After all the dimensions were decided and cg was successfully calculated, which was $30 \%$ of our chord length $=0.30 \times 8=2.4$ inches from leading edge of wing. We now moved on with our final fabrication process in which we started construction from wing.

We used hot wire machine which we made ourselves to cut foam into 2 identical parts in the shape of airfoil NACA 4415 which was placed on both ends of foam for each wing. 
Whole wing was constructed in two identical wings which were half of main wing and were 24 inches length and 8 inches in width as shown in Figure 1:

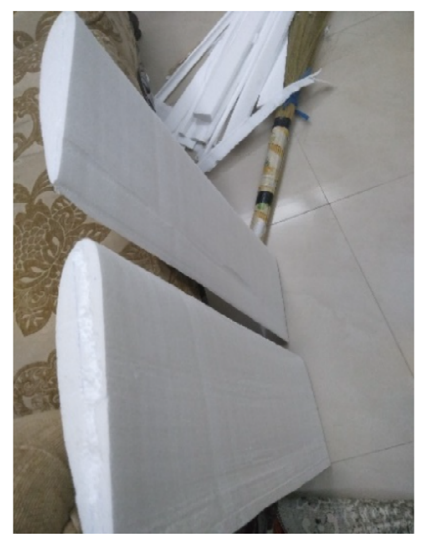

Figure 1. Separate Wings.

Source: own elaboration.

Now we joint them using german glue and to reinforce them properly we placed 1 SPAR (Figure 2) on top of them and 2 spar on the back, this gives foam extra rigidity which helps the wing to fly stably and smoothly.

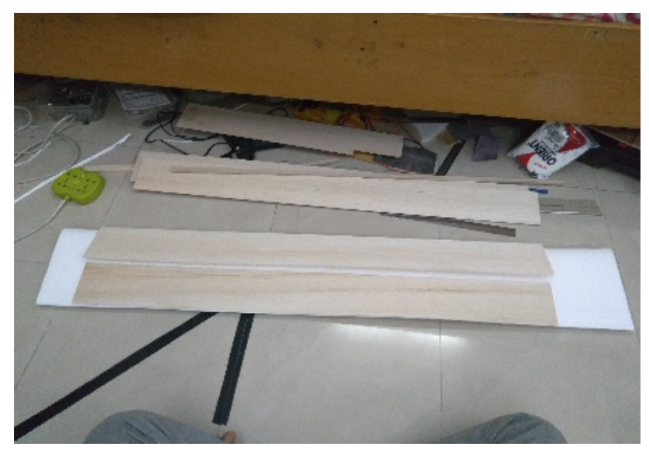

Figure 2. Joint Wings.

Source: own elaboration.

Next step to finish wing is to cut the ailerons on them, we used balsa as our ailerons and they were $22 \times 1.1$ inches in dimensions.

Using hinges (Figure 3) we made them movable in particular direction and using control horns we connected them to servo motors. 


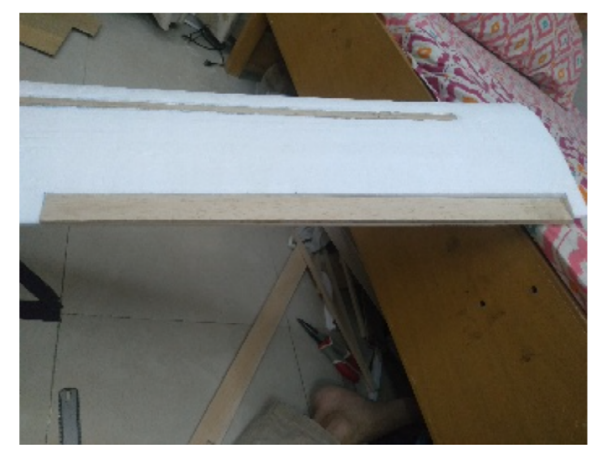

Figure 3. Ailerons.

Source: own elaboration.

Next part we started fabricating was fuselage (Habermann et al., 2021) (Figure 4), exactly like wing, we cut 2 identical shape of fuselage and joined them.

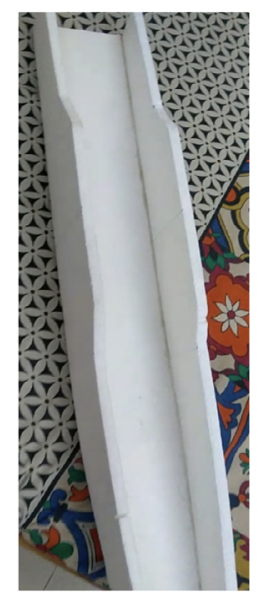

Figure 4. Fuselage body Source: own elaboration.

Our next step was to join the wing with the fuselage (Figure 5).

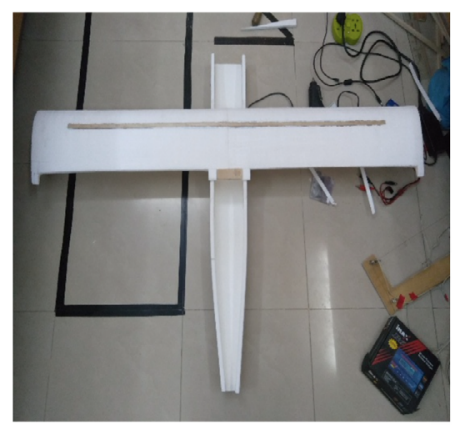

Figure 5. Wings and Fuselage.

Source: own elaboration. 
Now we cut our elevator (h-stab) (Figure 6) which is the main part of flying mechanism of plane.



Figure 6. Horizontal Stabilizer.

Source: own elaboration.

We reinforced (SPAR) by using balsa wood on both sides. At this point our plane was half ready (Figure 7).

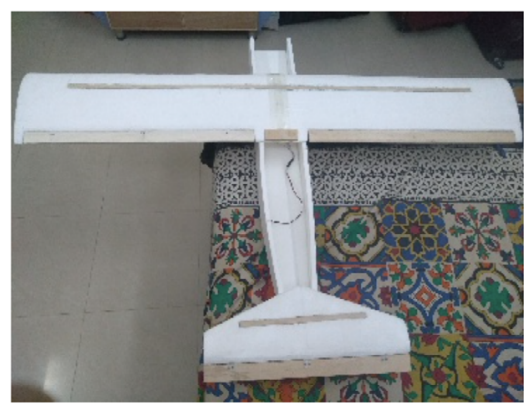

Figure 7. Extra Reinforcement.

Source: own elaboration.

After that we placed servos on the fuselage (Figure 8).



Figure 8. Servo motors.

Source: own elaboration. 
Next (V-stab) was fabricated and attached on the elevator (Figure 9).

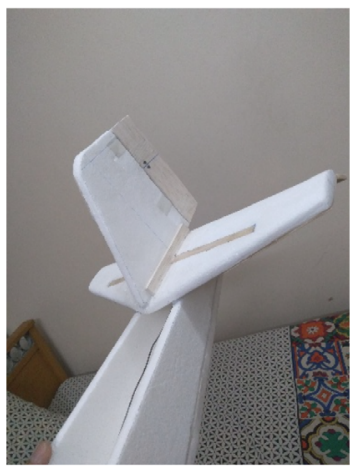

Figure 9. Vertical Stabilizer Attached with Horizontal Stabilizer.

Source: own elaboration.

Now before we move towards wrapping the body of the plane, it was necessary to do some reinforcement (Figure 10) to better strength.

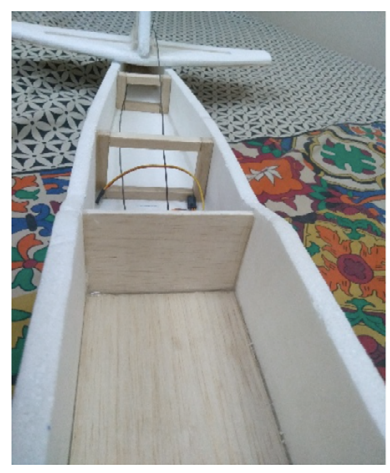

Figure 10. Fuselage Reinforcement.

Source: own elaboration.

Next step was mounting the motor (Figure 11) after which our plane was $90 \%$ ready.

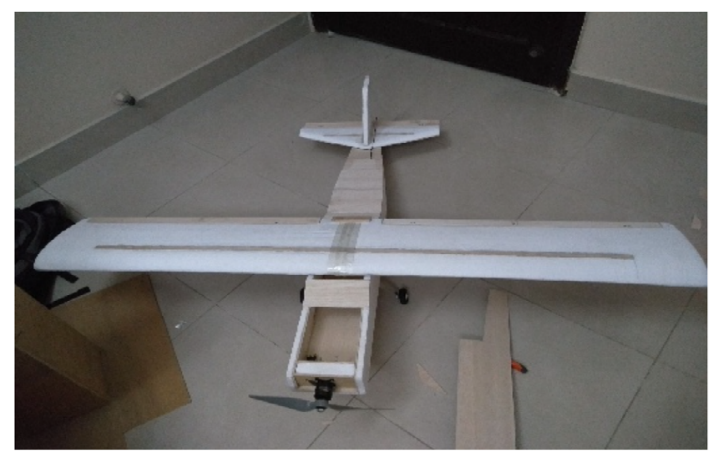

Figure 11. Final Body.

Source: own elaboration. 
After motor was mounted, our last was to attach the wings with fuselage. This was done using two strong elastics. After complete assembly our plane was completely ready (Figure 12) for our first test flight.

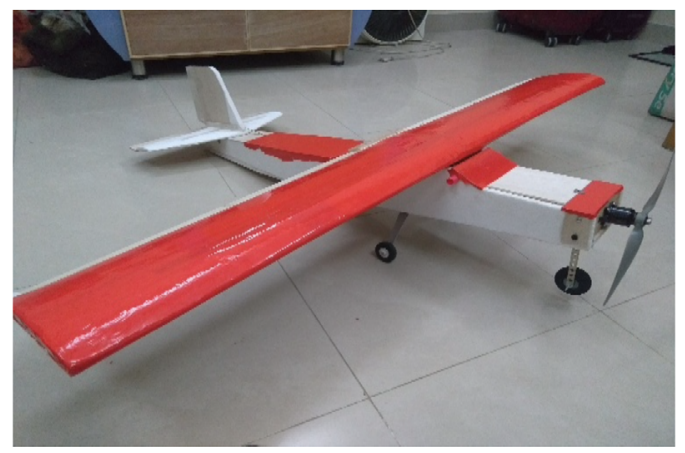

Figure 12. Completely built RC Plane.

Source: own elaboration.

\subsection{CFD ANALYSIS}

CFD or computational fluid dynamics analysis is considered as the important and the useful step when designing the RC or a big airplane (Petit et al., 2020). It is done to basically analyze either the wing selected for the plane is suitable for a good lift and drag of the RC model or not (Usherwood et al., 2020). This analysis can be done using different software. For our RC Plane model wing analysis, we used solid works. The data gathered by the analysis is given in following (Figure 13) and CFD domain size (Table 1).

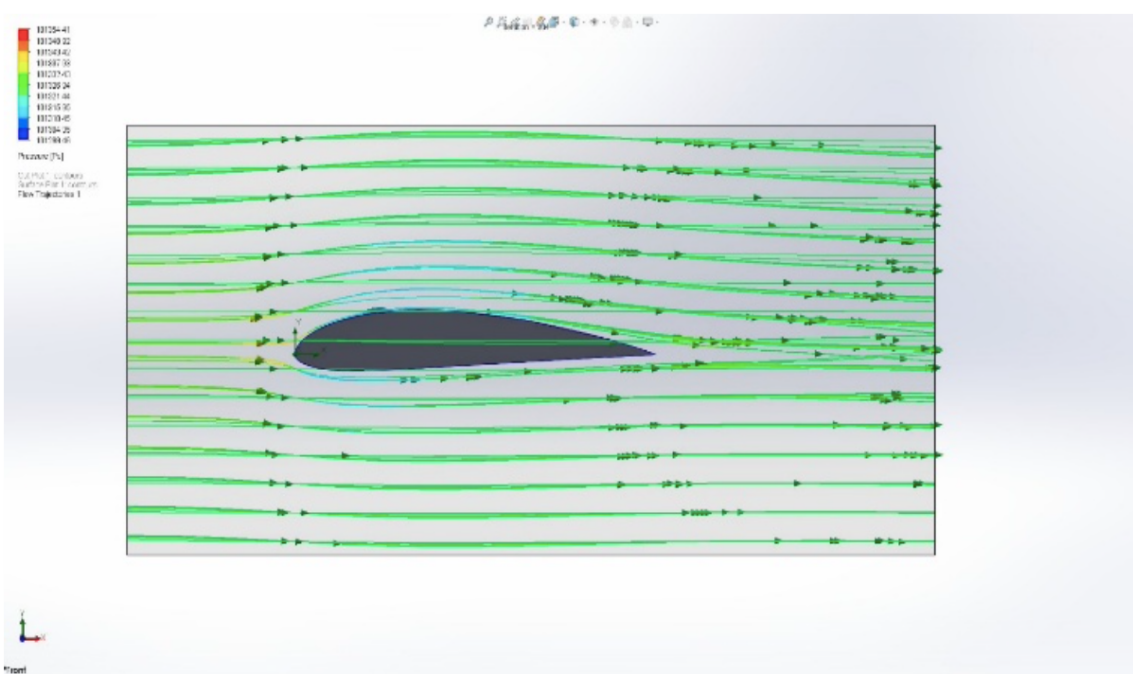

Figure 13. CFD Analysis.

Source: own elaboration. 
Table 1. CFD Domain Size

Source: own elaboration.

\begin{tabular}{|c|c|}
\hline $\mathrm{X} \min$ & $-0.095 \mathrm{~m}$ \\
\hline $\mathrm{X} \max$ & $0.361 \mathrm{~m}$ \\
\hline $\mathrm{Y} \min$ & $-0.103 \mathrm{~m}$ \\
\hline $\mathrm{Y} \max$ & $0.118 \mathrm{~m}$ \\
\hline $\mathrm{Z} \min$ & $-0.095 \mathrm{~m}$ \\
\hline $\mathrm{Z} \max$ & $1.314 \mathrm{~m}$ \\
\hline $\mathrm{X}$ size & $0.456 \mathrm{~m}$ \\
\hline $\mathrm{Y}$ size & $0.221 \mathrm{~m}$ \\
\hline $\mathrm{Z}$ size & $1.409 \mathrm{~m}$ \\
\hline
\end{tabular}

Table 2. Specifications.

\begin{tabular}{|l|l|}
\hline DESIGN PARAMETERS & VALUES \\
\hline Weight limit & $800 \mathrm{grams}$ \\
\hline Transmitter bandwidth & $2.4 \mathrm{GHz}$ \\
\hline Weight when empty & $350 \mathrm{grams}$ \\
\hline Length & 36 inch \\
\hline Wing span & 48 inch \\
\hline Engine type & BLDC motor 2216-1150KV \\
\hline Range & $2 \mathrm{~km}$ \\
\hline Velocity & ------ \\
\hline Material & Thermacole and balsa wood \\
\hline Angle of attack & $2^{\circ}$ \\
\hline
\end{tabular}

Source: own elaboration.

\subsection{PARTS AND COMPONENTS OF RC PLANE}

After design and analysis of our RC plane was done, the second step was to fabricate it. The building process requires proper selection of components and parts to make it fly with great efficiency and achieve its goal. As the controlling part of the RG plane we used Fly sky i6X transmitter and Fly sky iA6B receiver.

\subsubsection{TRANSMITTER}

The reason of using this transmitter is its low power consumption along with high receiver sensitivity. 
The Omni-directional high gain antenna's high efficiency reduces interference while using less power and maintaining a solid, stable link (Saeed et al., 2020).

\subsubsection{RECEIVER}

FS-iA6B is a 6 channel receiver which supports (PPM) pulse position modulation output with i-bus and data acquisition interface

\subsubsection{NACA 4415 AIRFOIL}

The airfoil works on principle of aerodynamics. Lift by an airfoil is generated when a downward force is exerted on the air. Lift is basically the upward force created by an airfoil. The shape of airfoil is such that it creates longer path at upper side of it for air to flow. This makes air molecules to move faster at upper area producing low pressure according to Bernoulli equation. At the lower side of airfoil air molecules travel smaller distance to meet trailing edge producing high pressure. This difference of pressure creates lift. When design of an air foil changes it also changes its lift coefficient with variation in Angle of attack (AOA) (also called as alpha).

The airfoil used for our RC plane is NACA 4415. This airfoil can produce lift even at low speed which make is more suitable or an RC plane. According to Data and analysis of this air is shown in Figure 14 and Graphics 1, 2, and 3.

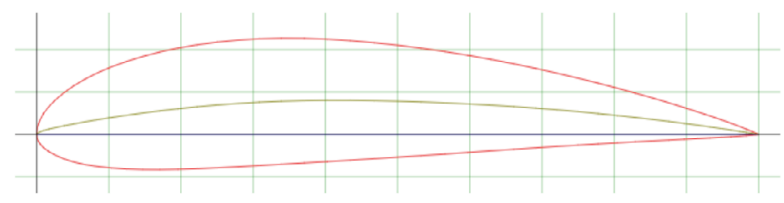

Figure 14. NACA 4415 Graph.

Source: own elaboration.

\subsubsection{LIFT VS DRAG COEFFICIENT}

Lift vs drag coefficient is normally called as the amount of lift that is generated by the airfoil as compared to its drag. This can be obtained by dividing lift coefficient by drag coefficient that are shown in Graphics 2 and 3. lift vs drag coefficient is used to represents the efficiency of an airfoil. The higher the $\mathrm{L} / \mathrm{D}$ ration the more efficiency the airfoil will produce. Suppose an aircraft is flying steadily, the drag produced by it will be minimum. 


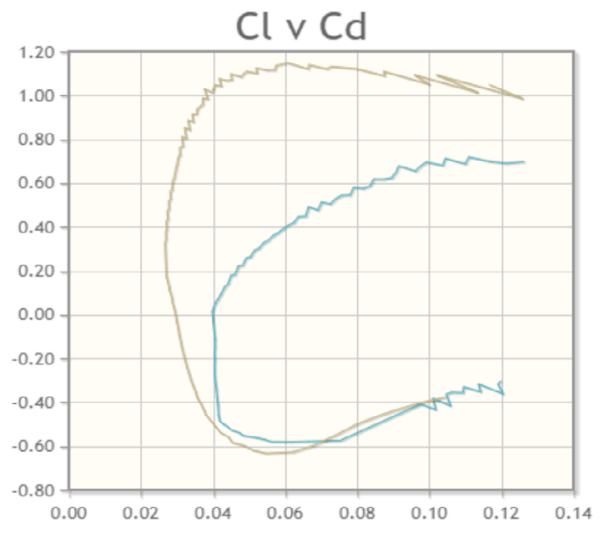

Graphic 1. CL Vs CD

Source: own elaboration.

\subsubsection{LIFT COEFFICIENT VS ALPHA}

The Graphic 2 show how coefficient of lift is effected when you change the AoA of an airfoil. On the x-axis we have AoA from -15 to 20 and on why y-axis we have coefficient of lift. Observe the reading at AOA 0-degree lift is somewhere around 0.38. if we increase AOA the lift will increase and if we reduce AOA the lift will decrease.

Graphic 2. CL Vs Alpha.

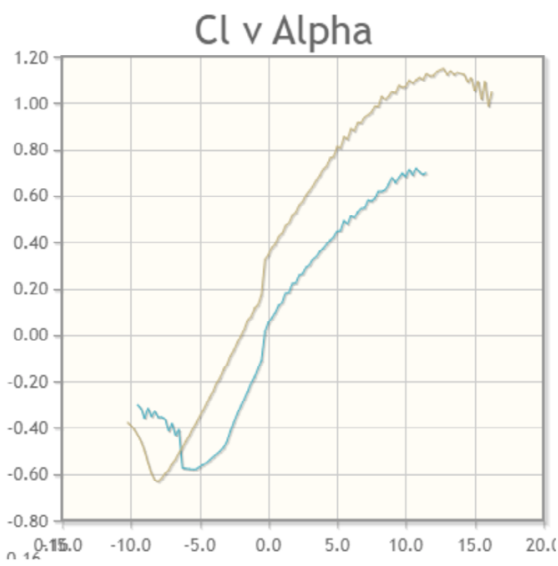

Source: own elaboration.

\subsubsection{DRAG COEFFICIENT VS ALPHA}

Drag is basically known as resistance that an object face in a medium. It is the value that a plane face while trying to generate lift. By looking at the graph below we can clearly see that at 0 AOA drag is lowest which shows less aerodynamic (Marinho et al., 2011). As the 
AOA is increased drag and lift is increased but when AOA in reduced drag increased and lift is decreased.

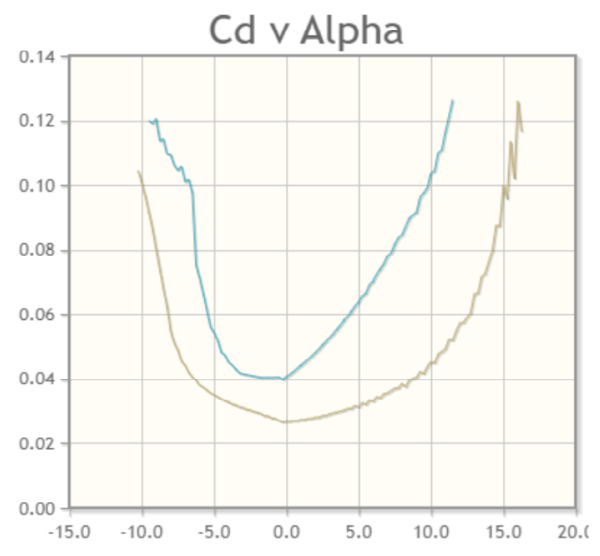

Graphic 3. CD Vs Alpha.

Source: own elaboration.

\section{RESULTS}

After fully completing the building process of our RC plane we were ready of our first test flight. The results were as we expected, the takeoff and landing of the plane was smooth and the flight was also good in even windy conditions.

\section{CONCLUSIONS}

After flying and performing different analysis on our plane we found that airplanes have so much potential in performing different tasks in different applications which could improve economy of country as well as provide alternative solutions for better technology used now a days.

\section{REFERENCES}

Azeez, A. A., Gadala, M., Khudhiri, N. A., \& Dol, S. S. (2019). Aerodynamics optimization of $\mathrm{RG}$ plane winglet. In 8th International Conference on Modeling Simulation and Applied Optimization, ICMSAO 2019. https://doi.org/10.1109/ ICMSAO.2019.8880426 
Habermann, A. L., Gokhale, A., \& Hornung, M. (2021). Numerical investigation of the effects of fuselage upsweep in a propulsive fuselage concept. CEAS Aeronautical Fournal. https://doi.org/10.1007/s13272-020-00487-2

Marinho, D. A., Silva, A. J., Reis, V. M., Barbosa, T. M., Vilas-Boas, J. P., Alves, F. B., Machado, L., \& Rouboa, A. I. (2011). Three-dimensional CFD analysis of the hand and forearm in swimming. Fournal of Applied Biomechanics. https://doi. org/10.1123/jab.27.1.74

Petit, H. A., Paulo, G. I., Cabrera, O. A., \& Irassar, E. F. (2020). Modelling and optimization of an inclined plane classifier using CFD-DPM and the Taguchi method. Applied Mathematical Modelling. https://doi.org/10.1016/j.apm.2019.07.059

Saeed, A., Mithaiwala, H. M., Hussain, A. I., \& Kumar, T. (2020). Development of smart painting machine using image processing. 3C Tecnología. Glosas de Innovación Aplicadas a La Pyme, 95-119. https://doi.org/10.17993/3ctecno/2020. v9n4e36.95-1 19

Usherwood, J. R., Cheney, J. A., Song, J., Windsor, S. P., Stevenson, J. P. J., Dierksheide, U., Nila, A., \& Bomphrey, R. J. (2020). High aerodynamic lift from the tail reduces drag in gliding raptors. Fournal of Experimental Biology. https://doi. org/10.1242/jeb.214809

Visnuprasad, A. K., Reby Roy, K. E., Jojo, P. J., \& Sahoo, B. K. (2019). Comparison of results from indoor radon measurements using active and passive methods with those from mathematical modeling. Radiation and Environmental Biophysics. https://doi. org/10.1007/s00411-019-00804-2 